\title{
Season and prey type influence size dependency of predator-prey body mass ratios in a marine fish assemblage
}

\author{
Jonathan C. P. Reum ${ }^{1,3, *}$, Mary E. Hunsicker ${ }^{2}$ \\ ${ }^{1}$ School of Aquatic and Fishery Sciences, University of Washington, Seattle, Washington 98195, USA \\ ${ }^{2}$ College of Earth, Ocean, and Atmospheric Sciences, Oregon State University, Corvallis, Oregon 97331, USA \\ ${ }^{3}$ Present address: Conservation Biology Division, Northwest Fisheries Science Center, National Marine Fisheries Service, \\ National Oceanic and Atmospheric Administration, 2725 Montlake Blvd. E, Seattle, Washington 98112, USA
}

\begin{abstract}
Marine and freshwater food webs are strongly structured by size-dependent predator-prey interactions. Predator-prey body mass ratios (PPMR) are important parameters in sizebased food-web models, but studies evaluating the temporal stability of PPMR or its relationship to predator feeding modes are scant. Using a large data set of predator-prey pairs from a diverse fish community sampled in summer, fall, and winter, we showed that community-level PPMR varied with predator mass in a nonlinear (dome-shaped) manner. PPMR was higher in the summer relative to the fall and winter for all predator body size classes regardless of whether prey were fish or invertebrate. Further, the size dependency of PPMR was dome-shaped for invertebrate prey but positive and linear for fish prey. We empirically show that community-level PPMR is dynamic rather than fixed, which is in agreement with general expectations set by simulation studies of biomass spectra. However, we are presently unable to identify the specific processes underlying these patterns. Size-based models of marine ecosystems offer considerable promise over traditional taxa-based approaches, and our analyses provide insight into major patterns of variation in PPMR in a temperate marine system.
\end{abstract}

KEY WORDS: Body mass - Demersal fish - Feeding interactions - Food web $\cdot$ Puget Sound · Size spectra $\cdot$ Trophic level

\section{INTRODUCTION}

Body size is a fundamental attribute of an organism that imposes constraints on both physiological rates and ecological interactions (Peters 1983). In marine and freshwater systems, body size is strongly related to trophic position because predators are generally larger than their prey (Cohen et al. 1993, Brose et al. 2006, Barnes et al. 2010). Consequently, energy is transferred from primary producers to consumers of successively larger sizes at each trophic step (Kerr \& Dickie 2001). Moreover, marine animals can grow 5 or more orders of magnitude in size over their life history and occupy different trophic levels at different stages. Thus, body size can often prove more informative of food-web position than species identity (Jennings 2005). For this reason, size-based food-web models, which describe biomass spectra (the distribution of biomass across body size classes), hold considerable promise over species-based models (Jennings 2005) and are increasingly utilized as tools to summarize and predict the effects of fishing and climate on marine ecosystems (Jennings \& Blanchard 2004, Law et al. 2012, Rochet \& Benoit 2012). 
Predator-prey body mass ratios (PPMR) are a key parameter in size-based models of energy flow, because they influence oscillatory dynamics in biomass spectra and, ultimately, the long-term accumulation of biomass across body size classes at the ecosystemlevel (Law et al. 2009, Hartvig et al. 2011). Knowledge of mean PPMR in individual systems may also provide information on interaction strengths (Jonsson \& Ebenman 1998, Emmerson \& Raffaelli 2004, VucicPestic et al. 2010), food-chain length (Jennings \& Warr 2003), and trophic transfer efficiency (Jennings 2005, Barnes et al. 2010). The need to better understand size-based interactions that underlie biomass spectrum dynamics has motivated multiple efforts to synthesize information on predator-prey pairs from a diverse collection of terrestrial, freshwater, and marine systems (Brose et al. 2005, Barnes et al. 2008). Analyses based on the pooled data indicate that PPMR differs among predator types (e.g. filter feeders, herbivores, carnivores; Brose et al. 2006) and increases as a function of predator body size (Barnes et al. 2010). This latter finding implies that, on average, transfer efficiency in marine food webs declines with increasing trophic level (Barnes et al. 2010). Such cross-system estimates of PPMR are valuable for developing general size-based models of food-web structure, but the extent to which these patterns emerge in any given system is untested.

Recent simulation studies suggest that, in marine systems, realized PPMR (i.e. as estimated with stomach content data) should change over time based on relative prey abundance (Law et al. 2009, Hartvig et al. 2011). Under this conceptualization of size-based food webs, realized PPMR should be related to the preferred PPMR of predators (which is based on behavioral constraints) and the relative availability of prey from different body size classes (Hartvig et al. 2011). In temperate systems, plankton production and larval and juvenile abundances are usually highest in the spring and summer months, resulting in a seasonal pulse of small-bodied prey (Strickland 1983, Kerr \& Dickie 2001). If predators are partially opportunistic in terms of prey size, we might expect realized PPMR to increase in the summer when small-bodied prey are more abundant relative to large-bodied prey. The expectation of a seasonal increase in realized PPMR draws upon principles observed in optimal foraging theory. Under low prey densities the functional response of predators is constrained by encounter rates and under high densities by handling time and the maximum possible feeding rate. However, handling time is usually inversely proportional to prey size (Thompson 1975, Aljetlawi et al. 2004), which suggests we might expect higher attack rates on small-bodied prey (and thus an increase in realized PPMR) accompanying increases in their densities. This general pattern has been observed in terrestrial invertebrate (e.g. Vucic-Pestic et al. 2010, Rall et al. 2011) and aquatic predatorprey systems (e.g. Wahlstrom et al. 2000, Aljetlawi et al. 2004).

Further, we might anticipate that realized PPMR should vary nonlinearly with predator body size, because the relationship between relative prey abundance and prey body size is not strictly linear. In addition to an overall negative slope, marine biomass spectra possess a secondary scaling consisting of domes and troughs associated with traveling waves (Kerr \& Dickie 2001) that result from predator-prey interactions possibly governed by the preferred PPMR predators and the span of prey sizes predators feed across (Law et al. 2009, Hartvig et al. 2011). Nonlinearity in the size dependency of realized PPMR might therefore emerge as a consequence of differences in the relative abundance of large- and smallbodied prey resulting from this secondary scaling, even if the preferred PPMR of predators remains invariant across predator size classes (Hartvig et al. 2011). Simulations of biomass spectra suggest that realized PPMR should vary temporally and nonlinearly with predator body size (Law et al. 2009, Hartvig et al. 2011); however, empirical evidence confirming such patterns in natural food webs is lacking.

Here, we tested whether size dependency and seasonality in realized PPMR (hereafter referred to as 'PPMR') was detectable within a well-sampled temperate marine fish community. We also considered the influence of prey type on PPMR, because the transition from invertivory to piscivory may necessitate changes in foraging behavior (Juanes et al. 2001) and is associated with known shifts in PPMR among fishes (Cohen et al. 1993). A growing body of evidence suggests further that the functional response of predators may depend not only on prey size but also on taxonomy (Rall et al. 2011). Seasonal changes in the relative availability of different prey groups, or the prevalence of piscivores relative to invertivores in general, may potentially influence communitylevel patterns of PPMR. For this reason, we considered whether predator body size, season, prey type (fish or invertebrate), or an interaction thereof, influenced PPMR. We hypothesized that PPMR increases during the summer when small-sized prey are more available. We also hypothesized that the transition from invertivory to piscivory accompanies a reduction in PPMR as observed in other studies (Cohen et 
al. 1993). Pronounced seasonality in PPMR may indicate that transfer efficiency and food-chain length vary intra-annually and that estimates of PPMR based on diet data sampled in one season alone may not necessarily correspond to an annual mean PPMR. Further, if PPMR varies with prey type, betweenecosystem differences in PPMR may be partially related to the prevalence of different feeding modes (e.g. piscivory vs. invertivory) and therefore species composition.

\section{MATERIALS AND METHODS}

\section{Data set}

We obtained stomach content information from fish predators sampled as part of a larger effort to characterize spatio-temporal variability in the Puget Sound marine food web (Reum \& Essington 2008). Sampling was performed along the eastern coastline of central Puget Sound at 6 stations spaced $\sim 6$ to $10 \mathrm{~km}$ apart. At each station, 4 depths $(20,40$, 80 , and $160 \mathrm{~m}$ ) were sampled using a benthic trawl. Sampling occurred in October 2004 and March and July 2005. Full details of the sampling gear, survey design, and catch processing are available elsewhere (Reum \& Essington 2008). Small fish retained for diet analyses $(<15 \mathrm{~cm}$ total length) were frozen for subsequent processing. Large fish $(\geq 15 \mathrm{~cm})$ were dissected, and predator stomachs that held contents were frozen or preserved in $80 \%$ ethanol. Length or weight measurements were recorded for all fish predators.

In the laboratory, stomach contents were identified to the lowest taxonomic level possible and enumerated. Length and weight measurements were recorded to the nearest $\mathrm{mm}$ and $0.01 \mathrm{~g}$, respectively. In some instances, small invertebrate prey (e.g. copepods, amphipods) belonging to the same species were counted but weighed together in order to estimate a mean mass. When possible, we also estimated the original mass of partially digested fish and invertebrate prey if intact vertebrae or carapaces were recovered using length-weight relationships (fish: www.fishbase.org; invertebrates: J. Reum unpubl. data).

\section{Statistical analysis}

Our analysis proceeded in 2 phases. In the first phase, we evaluated 4 candidate models in which
PPMR varied as a function of (1) predator body size, (2) season, (3) body size and season, or (4) body size, season, and their interaction. In the second phase we developed a second set of candidate models that included a base model (the best performing model from the first phase) and several additional models that included prey type (fish or invertebrate) in combination with variables included in the base model. We divided our analysis in this manner because we sought to estimate PPMR irrespective of prey type for comparison with previously published studies that disregarded prey identity and to narrow the number of plausible candidate models considered in the second phase.

Preliminary data exploration indicated nonlinearity in the relationship between PPMR and predator mass. Furthermore, the hierarchical nature of our data set (multiple prey collected from the same predator, multiple predators of the same species) meant that standard linear models of PPMR would be inappropriate due to violations of independence. To accommodate these issues, we analyzed the data using generalized additive mixed effects models (GAMMs; Wood 2006). In GAMMs, the response variable is assumed to be a sum of separate individual smooth spline functions (1 for each predictor variable; Wood 2006). The degree of nonlinearity corresponding to the spline functions is optimized using generalized cross validation, which takes into account the improvement in model fit and loss of degrees of freedom that accompany increased complexity of the response curves. The routine provides an objective method for calculating the optimal flexibility of the spline (Wood 2006). To improve variance homogeneity, both PPMR and predator mass were $\log _{10}$-transformed. Random slope and intercepts were estimated for each species, and random intercepts were included for individual predators (individual predators nested in predator species).

To identify the best model in the first phase of analysis, we evaluated model performance using Akaike's information criterion (AIC):

$$
\mathrm{AIC}=-2 L+2 k
$$

where $L$ is the restricted maximum log-likelihood of the fitted GAMM and $k$ is the number of parameters (Burnham \& Anderson 2002, Zuur et al. 2009). We calculated Akaike weights $(w)$ which convey the probability in favor of the $i$ th model conditional on the candidate model set $R$ (see Table 1) and given the data. The formula is as follows: 


$$
W_{i}=\frac{\exp \left(-\frac{1}{2} \Delta_{i}\right)}{\sum_{r=1}^{R} \exp \left(-\frac{1}{2} \Delta_{r}\right)}
$$

where $\Delta_{i}$ is the difference in the AIC between the best-performing model (lowest AIC) and the ith model (Burnham \& Anderson 2002, Anderson 2008). Values of $w_{i}$ range between 0 and 1 , corresponding to the likelihood that the $i$ th model is the best fit given the candidate model set (Anderson 2008).

To develop the second set of candidate models, we first identified variables included in the $95 \%$ confidence model set from the first phase of analysis (i.e. models with the largest $w$ values that sum to 0.95; Burnham \& Anderson 2002). These variables were then used to develop a base model that lacked terms corresponding to prey type (fish or invertebrate). Next, we constructed alternative models in which prey type and its interaction with the remaining variables from the base model were considered. As with the first model set, we identified the weight of evidence in favor of each model $(w)$ given the candidate model set. To visualize the estimated mean community-level relationships between predator mass, season, and prey type with PPMR we used model averaging, which weights the predicted values of each model by their corresponding $w$ values (Burnham \& Anderson 2002). All analyses were performed using the software package R v. 2.09 (R Development Core Team 2009) and the statistical library 'mgcv' (Wood 2006).

\section{RESULTS}

In total, we obtained stomach content data from 517,317 , and 585 individual predators that yielded 770,438 , and 1182 unique predator-prey pairs from October, March, and July, respectively. Collectively, 27 predator species were included in the data set and accounted for $96 \%$ of the total fish biomass captured in the survey. Individual predator sizes ranged up to 3 orders of magnitude within some species, e.g. Theragra chalcogramma (walleye pollock), Parophrys vetulus (English sole), Citharichthys sordidus (Pacific sanddab), Merluccius productus (Pacific hake), and spanned $\sim 4$ orders of magnitude across all species combined (Fig. 1). Piscivory was observed in 13 species and accounted for 219 predator-prey pairs $(9 \%$ of all predator-prey pairs; Fig. 1).

In the first phase of analyses, we examined a candidate model set that included predator mass and sea-

sonal effects on PPMR irrespective of prey type (Table 1). The best performing model consisted of a nonlinear smooth spline function of predator mass and season (Model 1B; Table 1). This model was strongly supported by the data $(w=1$; Table 1$)$. Examination of the partial effect and residual plots indicated that PPMR initially increased as a function of predator mass, peaked in predators weighing $\sim 100 \mathrm{~g}$, and then declined thereafter (Fig. 2a). Among seasons, PPMR was highest in summer and did not differ between fall and winter (Fig. 2b).

In the second phase of the analysis, we used Model 1B (the best fit model from the first phase) as a base model and constructed 4 additional candidate models that included main and interactive terms between predator body size, season, and prey type (invertebrate and fish prey; Table 2). The base model (Model 1B; no prey type terms) considerably underperformed the remaining models based on AIC

Squalus acanthias
Hydrolagus collie

Raja binoculata

Psettichthys melanostictus

Raja rhina

Sebastes ruberrimus

Pleuronichthys coenosus

Leptocottus armatus

M. polyacanthocephalus

Merluccius productus

Citharichthys sordidus

Lepidopsetta bilineata

Clupea pallasii

Sebastes maliger

Microstomus pacificus

Parophrys vetulus

Glyptocephalus zachirus

Porichthys notatus

Theragra chalcogramma

Lyopsetta exilis

Lycodes pacificus

Podothecus accipenserinus

Xeneretmus triacanthus

Microgadus proximus

Xeneretmus latifrons

Radulinus asprellus

Citharichthys stigmaeus$$
\text { (a) }
$$

ㅁ

$$
1
$$

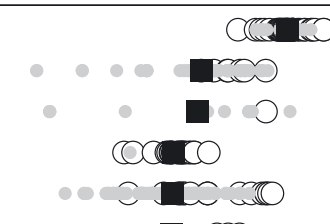

- $\mathrm{m}$

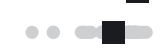

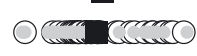

- 100
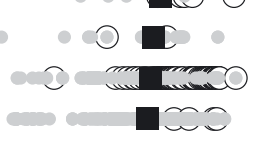

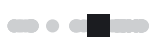

○ O

or
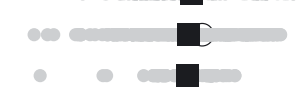

$+2$

(1)

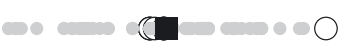

a

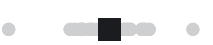

con

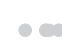

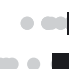

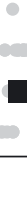

$\log _{10}$ predator mass (g)

Fig. 1. The body mass of fish predators sampled in Puget

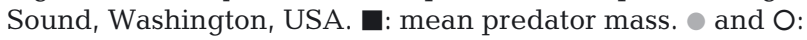
individual predators that consumed invertebrate and fish prey, respectively. $M .=$ Myoxocephalus 


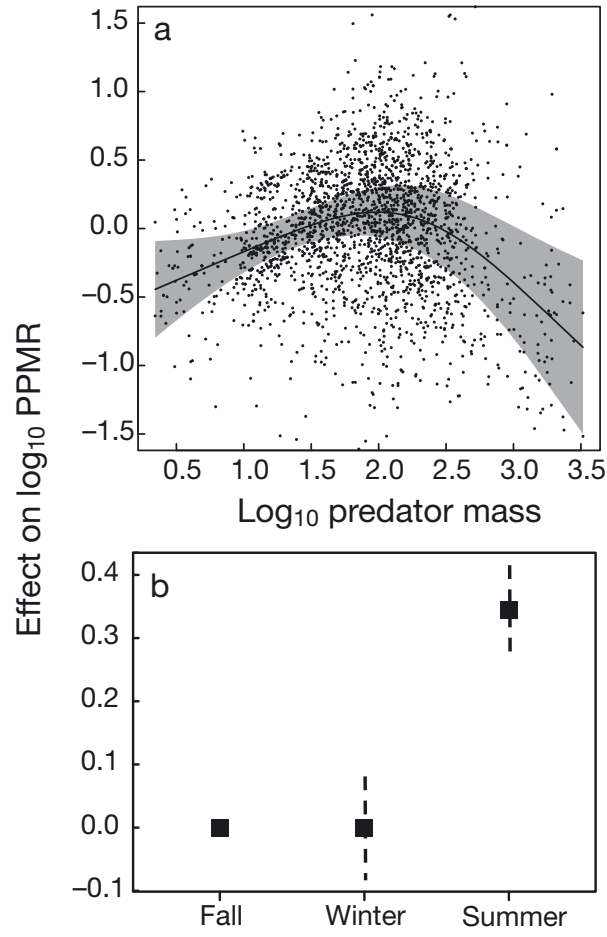

Fig. 2. Estimated partial effect of (a) predator mass and (b) season on $\log _{10}$ predator-prey mass ratios (PPMR) irrespective of prey type based on Model 1B. Partial residuals $(\bullet)$ and the estimated 95\% CI (shaded band) are depicted in (a). Error bars (b) correspond to $95 \%$ CI
(Table 2). Two models were included in the 95\% model confidence set. The best model (Model 2B, $w=0.79$ ) included prey type as a main effect, while the second best model (Model 2D, $w=0.21$ ) contained an additional interaction term between season and prey type (Table 2). Partial effect plots of the shared terms in Models 2B and 2D were qualitatively similar; therefore, we only presented partial effect plots of Model 2B. The functional relationship between PPMR and predator mass differed substantially between fish and invertebrate prey. PPMR for fish prey increased linearly with predator mass (Fig. $3 a)$, but was nonlinear and parabolic for invertebrate prey, with a maximum in PPMR occurring in predators that weighed $\sim 100 \mathrm{~g}$ (Fig. 3b). In addition, PPMR was higher overall for invertebrates relative to fish (Fig. 3c), while seasonal patterns in PPMR were similar to those observed in Model 1B: PPMR was highest in the summer (Fig. 3d).

For comparison, model-averaged predictions of PPMR from both the first and second sets of candidate models were depicted (Fig. 4a,b). Irrespective of prey type, mean PPMR during the summer was 1923, 3734, and 1143 among predators that weighed 10, 100, $1000 \mathrm{~g}$, respectively (Fig. 4a). In contrast, fall and winter PPMR estimates were lower: 863, 1258, and 501, respectively (Fig. 4b). PPMR estimates for

Table 1. Candidate models of predator-prey mass ratios considered in the first phase of analysis consisted of terms corresponding to predator mass and season. Prey type (fish or invertebrate) were disregarded in this phase. All models have identical random variable structure (individual predators nested in predator species; random slopes for each predator species). Models that include interactions between smooth spline functions $(s)$ and categorical variables (also known as variable coefficient models) indicate that a unique spline function is fitted to each factor level. For each model we give the negative restricted maximum log-likelihood

$(L)$, change in Akaike's information criterion $(\triangle \mathrm{AIC})$ relative to the best model (lowest AIC), and the Akaike weight ( $w$ )

\begin{tabular}{|c|c|c|c|c|c|}
\hline Model & Model description & $\mathrm{df}$ & $L$ & $\Delta \mathrm{AIC}$ & $w$ \\
\hline $1 \mathrm{~A}$ & $s$ (predator mass) & 8 & -2408.7 & 78.3 & $<0.001$ \\
\hline $1 \mathrm{~B}$ & $s$ (predator mass) + season & 10 & -2368.0 & 0 & 1 \\
\hline $1 \mathrm{C}$ & $s($ predator mass $)+$ season $+s$ (predator mass $) \times$ season & 14 & -2368.3 & 11.8 & $<0.001$ \\
\hline
\end{tabular}

Table 2. The best model from the first candidate model set (Model 1B) and 4 additional models (2A to 2D) that included prey type were considered in the second candidate model set. Variables corresponding to the fixed component of each model are presented. All models have identical random variable structure (individual predators nested in predator species; random slope for each predator species). For each model we give the negative restricted maximum log-likelihood $(L)$, change in Akaike's information criterion ( $\triangle \mathrm{AIC}$ ) relative to the best model (lowest AIC), and the Akaike weight $(w)$

\begin{tabular}{|c|c|c|c|c|c|}
\hline Model & Model description & df & $L$ & $\Delta \mathrm{AIC}$ & $w$ \\
\hline 1B & $s($ predator mass $)+$ season & 10 & -2368.0 & 384.91 & $<0.001$ \\
\hline $2 \mathrm{~A}$ & $s($ predator mass $)+$ season + prey type & 11 & -2182.7 & 16.21 & $<0.001$ \\
\hline 2B & $\begin{array}{l}s(\text { predator mass })+\text { season }+ \text { prey type }+s(\text { predator mass }) \times \\
\text { prey type }\end{array}$ & 13 & -2172.6 & 0 & 0.79 \\
\hline $2 \mathrm{C}$ & $s($ predator mass $)+$ season + prey type + season $\times$ prey type & 13 & -2182.6 & 20.07 & $<0.001$ \\
\hline 2D & $\begin{array}{l}s(\text { predator mass })+\text { season }+ \text { prey type }+ \text { season } \times \text { prey type }+ \\
s(\text { predator mass }) \times \text { prey type }\end{array}$ & 15 & -2171.9 & 2.66 & 0.21 \\
\hline
\end{tabular}



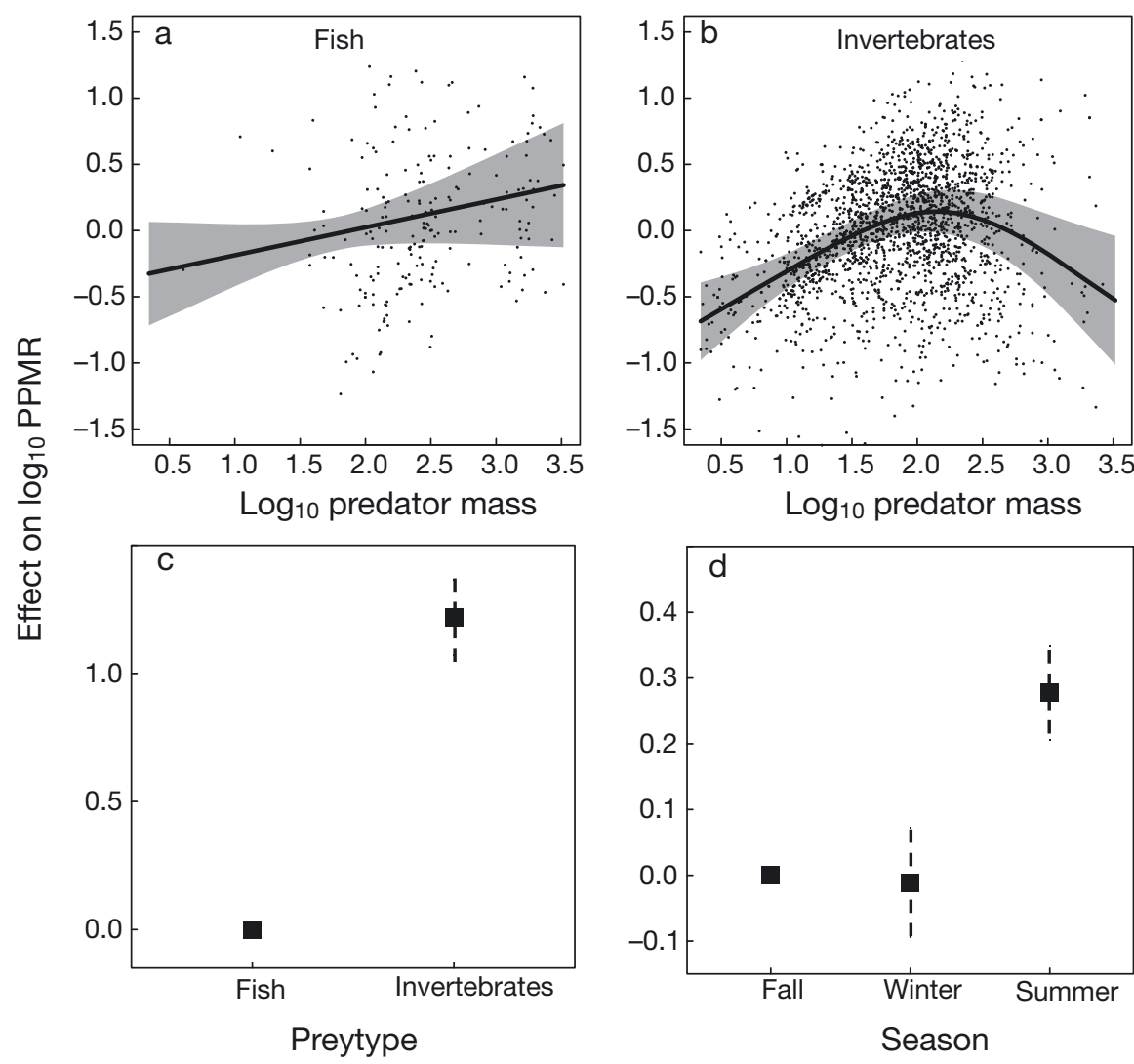

Fig. 3. Estimated partial effect of predator mass for $(a, b)$ fish and invertebrate prey, (c) prey type, and (d) season on $\log _{10}$ predator-prey mass ratios (PPMR) based on Model 2B. Partial residuals $(\bullet)$ and the estimated 95\% CI (shaded band) are depicted in (a) and (b). Error bars in (c) and (d) correspond to $95 \% \mathrm{CI}$

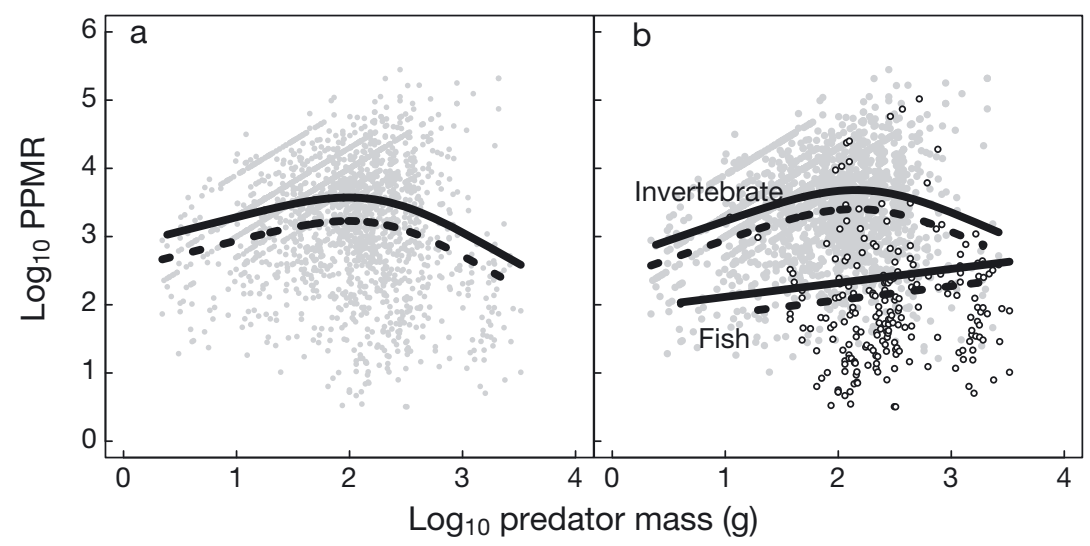

Fig. 4. (a) $\log _{10}$ predator-prey mass ratios (PPMR) versus predator mass for demersal fish predators from Puget Sound, Washington, USA, for all prey types. (b) $\log _{10}$ PPMR versus predator mass for invertebrate $(\odot)$ and fish prey (O). For both Panels a and b, the predicted community-level relationship is depicted for summer (solid line) and winter (dashed line) based on Model 1B and model-averaged predictions from Models 2B and 2D, respectively. Fall $\log _{10}$ PPMR relationships were nearly identical to those for winter and were therefore not plotted to aid clarity

invertebrate prey were relatively similar to those estimates based on both prey types, but PPMR for fish prey were considerably lower (summer: 285,343 , and 1231 for 10,100 , and $1000 \mathrm{~g}$ predators, respectively; Fig. 4b).

\section{DISCUSSION}

Community-level estimates of PPMR are rare in the literature, and previous studies that have quantified
PPMR have largely relied on data aggregated across systems, taxa, and over time (Cohen et al. 1993, Brose et al. 2006, Barnes et al. 2010). These estimates offer important insight into general patterns of $\mathrm{PPMR}_{i}$ however, they veil potentially complex patterns of variation that may emerge in individual food webs. Our main results indicate that over the predator body size range considered, PPMR varied in a nonlinear fashion. Further, we found that the size dependency of PPMR differed between prey types and that seasonal shifts in PPMR were relatively uni- 
form for both groups. These latter findings confirmed our hypothesis that PPMR should increase in the summer when invertebrate production and larval and juvenile fish abundances are usually highest in Puget Sound (Strickland 1983), and suggest that the size dependency of feeding modes differs in fundamental ways. The variation in PPMR observed in the Puget Sound fish community also suggests that estimates of PPMR are likely to vary for fish communities and marine systems depending on the prevalence of piscivory and the strength of seasonality in the annual production cycle.

Our finding of predator size dependency in PPMR differs from previous studies in important ways. Barnes et al. (2010) observed a positive linear relationship between predator mass and PPMR across taxa and ecosystems. In contrast, we found a curvilinear relationship. The highest PPMR values occurred in mid-sized fish predators within our data set $(\sim 100 \mathrm{~g})$, while PPMR values of smaller- and largerbodied predators were lower. If the PPMR of predators in Puget Sound is strongly associated with sizeor species-varying morphological or behavioral constraints, this may have induced nonlinearity into the size dependencies of PPMR. However, simple differences in the relative abundance of large- and smallbodied prey can also give rise to nonlinearity in PPMR, which is a general prediction of simulated biomass spectra (Law et al. 2009, Hartvig et al. 2011) and commonly observed in predator-prey functional response experiments (e.g. Wahlstrom et al. 2000, Vucic-Pestic et al. 2010). Identifying whether nonlinearity in the size dependency of PPMR in Puget Sound is related to morphological and behavioral constraints or is simply an emergent feature of the biomass spectrum remains a challenge because our knowledge of prey abundance is incomplete. Previous work indicates that production cycles in Puget Sound are typical of those found in coastal temperate systems with peak plankton densities occurring in the spring and summer months (Strickland 1983). However, obtaining quantitative estimates of prey abundance by size class is a major challenge. It requires sampling diverse marine communities in pelagic and rocky reef systems and hard- and softbottom benthic habitats at spatial scales comparable to those at which fish predators forage. If such data were available, it might permit the back-calculation of preferred PPMR, which is based on behavioral constraints, and potentially allow the parameterization of biomass spectrum models based on individuallevel size-based feeding interactions (Hartvig et al. 2011). At present we are unable to attribute the shape of the PPMR-predator body size relationship to any single process, but our results offer an empirical example of nonlinearity in the size dependency of community-level PPMR and suggest that the common assumption of size invariant PPMR in static biomass spectrum models (e.g. Jennings \& Blanchard 2004) should be revisited.

The observed seasonal variation in PPMR agreed with our general expectation that size dependences in predator-prey relationships should vary in response to changes in relative prey abundance even though the preferred PPMR of predators based on behavioral constraints may potentially remain fixed (Hartvig et al. 2011). The overall increase in PPMR during summer when plankton densities are highest (Strickland 1983) suggests that small-bodied prey appeared with greater frequency in diets at the community-level regardless of the predator's size. This pattern agrees with analyses of guild structure in the Puget Sound fish community which showed that zooplankton were more common in summer diets (Reum \& Essington 2008). Based on allometric arguments and assumptions underpinning theories of biomass spectra in aquatic systems, PPMR and trophic transfer efficiency are roughly inversely proportional (Barnes et al. 2010). This suggests that transfer efficiency is lowest in the summer and highest in the fall and winter in Puget Sound, a pattern qualitatively similar to that observed in pelagic lake food webs (Gaedke \& Straile 1994). Intra-annual dynamics in PPMR and thus transfer efficiency are rarely handled explicitly in size-based food-web models, and it is unclear how the inclusion of periodicities in these parameters might impact emergent features of biomass spectra. More broadly, if PPMR is sensitive to seasonal shifts in productivity, it may also vary over longer time scales and respond to climate modes (e.g. El Niño-Southern Oscillation, Pacific Decadal Oscillation) that are known to impact the relative abundance and size structure of autotrophic communities (Iriarte \& Gonzales 2004). Further work is needed to evaluate the linkages between climate and size structuring in marine food webs.

As with previous studies, we found that PPMR associated with fish prey was substantially lower than that of invertebrate prey among predators of the same size (Cohen et al. 1993, Juanes et al. 2001), but the difference in PPMR between prey types diminished as predator size increased. The large differences in PPMR, especially among mid-sized $(\sim 100 \mathrm{~g})$ predators, suggest that predator size-selectivity varies fundamentally between the 2 prey types. Previous experimental work indicates that some inverte- 
brate prey may be more difficult to capture than fish of comparable size because of the unpredictable nature of their flight responses (Juanes et al. 2001). Yet few other studies have investigated the mechanisms underlying the differences in predator sizeselectivity among fish and invertebrate prey. In addition to predator avoidance behavior, differences in encounter rates, energy gains, and handling times (Juanes et al. 2002) may also influence the size dependency of fish and invertebrate prey selection. More work is needed to clarify the mechanisms that drive these recurring differences in PPMR. However, regardless of the mechanism, the patterns observed in the present study suggest that estimates of PPMR in fish communities might vary between ecosystems depending on the relative abundance of piscivores.

Similar to other analyses of PPMR based on diet data (e.g. Brose et al. 2006, Barnes et al. 2010), our study has important caveats. First, our analysis used prey collected from stomach samples that in some instances were partially digested. The inclusion of these data meant that estimates of PPMR would likely be upwardly biased. However, we minimized the likelihood of this effect by calculating the original mass of prey with length data when possible and by excluding prey that were unidentifiable and therefore not usually intact. In addition, our results are based on the assumption that the relative abundances of differently sized prey in predator stomachs are proportional to the rates at which they are consumed. In fish, digestion rates are often slower for large-bodied prey, resulting in longer stomach residency times compared to small-bodied prey (Jobling 1994). This general tendency suggests that largebodied prey may potentially be overrepresented in the data relative to small-bodied prey, artificially lowering the observed PPMR. Digestion rates also vary by predator species and size and by prey body composition (Jobling 1994), but in the absence of species-specific information on prey digestion rates it is difficult to identify the magnitude of this error source. Finally, our analysis was limited to fish predators spanning $\sim 4$ orders of magnitude in size and may not necessarily be indicative of PPMR patterns in other taxonomic groups or body size classes in the Puget Sound food web. However, the species included in the analysis account for $\sim 90 \%$ of the total demersal fish biomass in Puget Sound (Quinnell \& Schmitt 1991) and therefore compose a major subset of the food web.

Our investigation compliments previous studies that have sought to identify key sources of variation in realized PPMR by synthesizing diet data across multiple taxa and ecosystems (Brose et al. 2006, Barnes et al. 2010). Such studies are essential for developing generalities and advancing theory, but at present may have limited potential for predicting PPMR values in individual food webs. Stomach content data aggregated across systems are poorly suited to test hypotheses regarding PPMR dynamics, because the functional relationship linking PPMR to predator size will vary depending on the relative abundance and body size distribution of prey which differ across food webs and over time (Law et al. 2009, Hartvig et al. 2011). Size dependencies detected in analyses of cross-system data sets, therefore, necessarily reflect phenomena that emerge at a level of organization higher than that of individual food webs. By examining PPMR patterns in a wellsampled individual food web, we offer evidence that size dependencies in PPMR may differ by season and, therefore, possibly over longer time scales as well. In addition, we confirm the general expectation of simulation studies which suggest that the relationship between realized PPMR and predator body size may take nonlinear forms (Law et al. 2009, Hartvig et al. 2011). We also note that we are currently unable to identify the specific processes underlying this pattern. To improve our understanding of size structuring in marine ecosystems we encourage the parallel pursuit of cross-ecosystem and -taxa comparisons in PPMR, as well as the collection of high-quality diet data from individual food webs. Identifying patterns of PPMR at both regional and global scales is integral to developing a unified understanding of size structuring in marine and freshwater food webs.

Acknowledgements. Funding for J.C.P.R. was provided by the Vincent Liguori Fellowship and the University of Washington Climate Impacts Group. Boat time was financed by a University of Washington Research Royalties Fund awarded to T. Essington. T. Essington and D. Schindler provided input and conversations that led to the development of this manuscript. M. Hartvig, B. Rall, and 2 anonymous reviewers provided helpful comments on earlier versions of the manuscript.

\section{LITERATURE CITED}

Aljetlawi AA, Sparrevik E, Leonardsson K (2004) Preypredator size-dependent functional response: derivation and rescaling to the real world. J Anim Ecol 73: 239-252

Anderson DR (2008) Model based inference in the life sciences: a primer on evidence. Springer, New York, NY

Barnes C, Bethea DM, Brodeur RD, Spitz J and others (2008) Predator and prey body sizes in marine food webs. Ecology 89:881 
Barnes C, Maxwell D, Reuman DC, Jennings S (2010) Global patterns in predator-prey size relationships reveal size dependency of trophic transfer efficiency. Ecology 91:222-232

Brose U, Cushing L, Berlow EL, Jonsson T and others (2005) Body sizes of consumers and their resources. Ecology 86: 2545

Brose U, Jonsson T, Berlow EL, Warren P and others (2006) Consumer-resource body-size relationships in natural food webs. Ecology 87:2411-2417

Burnham KP, Anderson DR (2002) Model selection and multimodel inference: a practical information-theoretic approach. Springer, New York, NY

Cohen JE, Pimm SL, Yodzis P, Saldana J (1993) Body sizes of animal predators and animal prey in food webs. J Anim Ecol 62:67-78

Emmerson MC, Raffaelli D (2004) Predator-prey body size, interaction strength and the stability of a real food web. J Anim Ecol 73:399-409

Gaedke U, Straile D (1994) Seasonal changes of trophic transfer efficiencies in a plankton food web derived from biomass size distributions and network analysis. Ecol Model 75/76:435-445

Hartvig M, Andersen KH, Beyer JE (2011) Food web framework for size-structured populations. J Theor Biol 272: 113-122

Iriarte J, Gonzales H (2004) Phytoplankton size structure during and after the 1997/98 El Niño in a coastal upwelling area of the northern Humboldt Current System. Mar Ecol Prog Ser 269:83-90

Jennings S (2005) Size-based analyses of aquatic food webs. In: Belgrano A, Shcarler UM, Dunne JA, Ulanowicz RE (eds) Aquatic food webs: an ecosystem approach. Oxford University Press, Oxford, p 86-97

> Jennings S, Blanchard JL (2004) Fish abundance with no fishing: predictions based on macroecological theory. J Anim Ecol 73:632-642

> Jennings S, Warr KJ (2003) Smaller predator-prey body size ratios in longer food chains. Proc R Soc Lond B 270: 1413-1417

Jobling M (1994) Fish bioenergetics. Chapman \& Hall, London

> Jonsson T, Ebenman B (1998) Effects of predator-prey body size ratios on the stability of food chains. J Theor Biol 193:407-417

Juanes F, Buckel J, Scharf F (2001) Predatory behaviour and selectivity of a primary piscivore: comparison of fish and non-fish prey. Mar Ecol Prog Ser 217:157-165

Editorial responsibility: Ivan Nagelkerken,

Nijmegen, The Netherlands
Juanes F, Buckel J, Scharf F (2002) Feeding ecology of piscivorous fishes. In: Hart PB, Reynolds JD (eds) Handbook of fish biology and fisheries, Vol 1. Blackwell Science, Oxford, p 238-267

Kerr S, Dickie LM (2001) The biomass spectrum: a predator-prey theory of aquatic production. Columbia University Press, New York, NY

Law R, Plank MJ, James A (2009) Size-spectra dynamics from stochastic predation and growth of individuals. Ecology 90:802-811

Law R, Plank MJ, Kolding J (2012) On balanced exploitation of marine ecosystems: results from dynamic size spectra. ICES J Mar Sci 69:602-614

Peters RH (1983) The ecological implications of body size. Cambridge University Press, New York, NY

Quinnell S, Schmitt C (1991) Abundance of Puget Sound demersal fishes: 1987 research trawl survey results. Washington State Department of Fisheries, Olympia, WA

Rall BC, Kalinkat B, Ott D, Vucic-Pestic O, Brose U (2011) Taxonomic versus allometric constraints on non-linear interaction strengths. Oikos 120:483-492

R Development Core Team (2009) R: a language and environment for statistical computing. R Foundation for Statistical Computing, Vienna. Available at: www.Rproject.org

Reum JCP, Essington TE (2008) Seasonal variation in guild structure of the Puget Sound demersal fish community. Estuaries Coasts 31:790-801

Rochet MJ, Benoit E (2012) Fishing destabilizes the biomass flow in the marine size spectrum. Proc Biol Sci 279: 284-292

Strickland RM (1983) The fertile fjord. Washington Sea Grant, Seattle, WA

Thompson DJ (1975) Toward a predator-prey model incorporating age structure: the effects of predator and prey size on the predation of Daphnia magna by Ischnura elegans. J Anim Ecol 44:907-916

Vucic-Pestic O, Rall BC, Kalinkat G, Brose U (2010) Allometric functional response model: body masses constrain interaction strengths. J Anim Ecol 79:249-256

Wahlstrom E, Persson L, Diehl S, Bystrom P (2000) Sizedependent foraging efficiency, cannibalism and zooplankton community structure. Oecologia 123:138-148

Wood SN (2006) Generalized additive models: an introduction with R. Chapman \& Hall/CRC, Boca Raton, FL

Zuur AF, Ieno EN, Walker N, Savellev AA, Smith GM (2009) Mixed effects models and extensions in ecology with R. Springer, New York, NY

Submitted: March 21, 2012; Accepted: June 28, 2012

Proofs received from author(s): September 25, 2012 